\title{
The White Death: Tragedy and Heroism in an Avalanche Zone
}

McKay Jenkins

New York: Random House, 2000

US \$23.95, 228 pages, hardcover

This masterful narrative is both history and science, a wonderful blend of avalanche instruction, mountain rescue history, and youthful high adventure. McKay Jenkins tells the story of 5 young climbers who, in 1969 , attempted a winter ascent of the yet unclimbed north face of Mount Cleveland, the highest peak in Glacier National Park. When they died in a gigantic avalanche, a massive search and rescue mission was undertaken. It didn't end until the following spring, when the 5 climbers' bodies were recovered.

Intertwined with the story of the boys' climbing lives and the ascent, Jenkins discusses avalanche science and mountain rescue history, including the first mountain rescue personnel of St Bernard's Monastery in Europe, the US Army's 10th Mountain Division, and avalanche safety techniques such as avalanche cords, rescue transceivers, and dogs. Interestingly, he is very thorough but leaves out cutting-edge experimental gear from wilderness medicine researchers like backpack airbags, breathing apparatus, and GPS technology.

Nonetheless, Jenkins puts you on the mountain and keeps you there for the whole book. It's a tragic tale with good writing and a mix of mountain rescue history and avalanche science to boot.

Christopher Van Tilburg White Salmon, WA, USA 